\title{
Endothelial and smooth muscle cell populations in a decellularized cryopreserved aortic homograft (SynerGraft) 2 years after implantation
}

\author{
Dylan V. Miller, M.D., ${ }^{\text {a }}$ William D. Edwards, M.D., ${ }^{\text {a }}$ Kenton J. Zehr, M.D., ${ }^{\text {b }}$ Rochester, Minnesota
}

丹 Supplemental material is available online.

\section{Introduction}

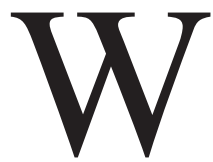

hile the cryopreserved homograft heart valve is an established option for patients requiring replacement of damaged or diseased aortic valves, there is evidence that valve durability may be negatively impacted by the allogenicity of residual viable cells. ${ }^{1}$ Decellularization techniques, like the SynerGraft process, reduce the cellular content of homograft valves, in hopes of modifying the host immune response to the graft. Uncertainty remains over the mechanism and extent of "recellularization" occurring in these decellularized grafts after implantation in humans. Characterization of cells populating the implanted decellularized grafts is important in understanding host adaptation and possibly in-vivo longevity of the grafts. This report details the histomorphologic and immunophenotypic features of cells identified in a decellularized (SynerGraft) aortic valve recovered two years after implantation.

\section{Clinical Synopsis}

At age 19, a male patient underwent replacement of his congenitally bicuspid aortic valve. At age 52, he underwent insertion of an aortic SynerGraft homograft for prosthetic aortic valve stenosis and an ascending aortic aneurysm. Postoperatively, left ventricular function did not improve significantly, and he underwent cardiac transplantation two years later. The explanted heart showed moderate left ventricular hypertrophy, coronary atherosclerosis, and an old transmural anteroseptal infarct. The homograft walls were pliable and noncalcified. The homograft valve cusps showed minimal fibrous thickening with focal calcification in the non-coronary valve pocket.

\section{Histopathology}

Aortic Wall. Histologic sections of the aortic root stained with hematoxylin-eosin and Verhoeff-van Gieson showed that the

From the Division of Anatomic Pathology, ${ }^{\mathrm{a}}$ and the Division of Cardiovascular Surgery, ${ }^{\text {b }}$ Mayo Clinic, Rochester, Minnesota.

Corresponding author: Dylan V. Miller, M.D. Mayo Clinic 200 First Street S.W. Rochester, MN 55905 Phone: 507-284-1192 FAX: 507-284-1599 E-mail: miller.dylan@mayo.edu

J Thorac Cardiovasc Surg 2006;132:175-6

$0022-5223 / \$ 32.00$

Copyright () 2006 by The American Association for Thoracic Surgery

doi:10.1016/j.jtcvs.2006.02.038
SynerGraft tissue was entirely devoid of nuclei, with the exception of the neointimal layer and focal cellular incursions into the superficial elastic media (Figure 1). Foreign body giant cell reaction surrounded the sewing ring, but the remainder of the graft tissue was free of inflammation. Focal microscopic dystrophic calcifications were present at the interface between the graft and the native aorta.

Valve Cusps. Cells were also observed lining the valve cusps and showed focal extension into the subjacent spongy layer. This was more prominent near their annular insertions. The most superficial cells had an endothelial appearance with flattened cytoplasm and elongated nuclei. Deeper cells (both in the aortic elastic media and in the valve spongiosa) had a plumper and more spindled appearance with an eosinophilic cytoplasm suggestive of myofibroblasts or smooth muscle cells.

\section{Immunohistochemistry}

Immunohistochemical staining of formalin-fixed paraffinembedded aortic root sections was performed using antibodies directed against CD31, CD34, factor VIII related antigen, smooth muscle actin (SMA), vimentin, CD68, CD3, CD20, and CD15. Antibody clones and reaction conditions are available on-line (Table E1). Figure 2 illustrates expression of selected antigens.

Staining for endothelial antigens (CD31, CD34, and Factor VIII related antigen) was seen primarily in flattened superficial neo-endocardial cells and focally within valvular capillaries. Staining for smooth muscle and myofibroblastic antigens (smooth muscle actin and vimentin) was confined to the deeper spindledappearing cells. Macrophage antigen (CD68) expression was seen in scattered cells within the intimal layer and superficial media of the aortic wall and extending up to $1 \mathrm{~mm}$ deep to the endothelium of the valve leaflets. No CD3 positive T-cells, CD20 positive B-cells or CD15 positive granulocytes were identified infiltrating the tissues, but reactivity for these antigens was seen in cells circulating within vascular lumens. No staining for any antigen was seen in the acellular homograft wall or deep cusp tissue, which served as negative internal controls.

\section{Discussion}

Only one other report has characterized cells within a decellularized homograft in humans - a patient who died 5 weeks after implantation of a pulmonary homograft. ${ }^{2}$ The graft showed infiltration by neutrophils and CD68 positive macrophages into only the most superficial aspect of the neointima. No smooth muscle, fibroblastic, or lymphocytic cells were identified by immunohistochemistry. Animal studies have demonstrated a sequence of early infiltration by macrophages occurring over the first few months, followed by fibroblast colonization (up to 11 months). ${ }^{3}$

The present case not only affirms the colonization process seen in animal models, but also demonstrates endothelial and smooth 

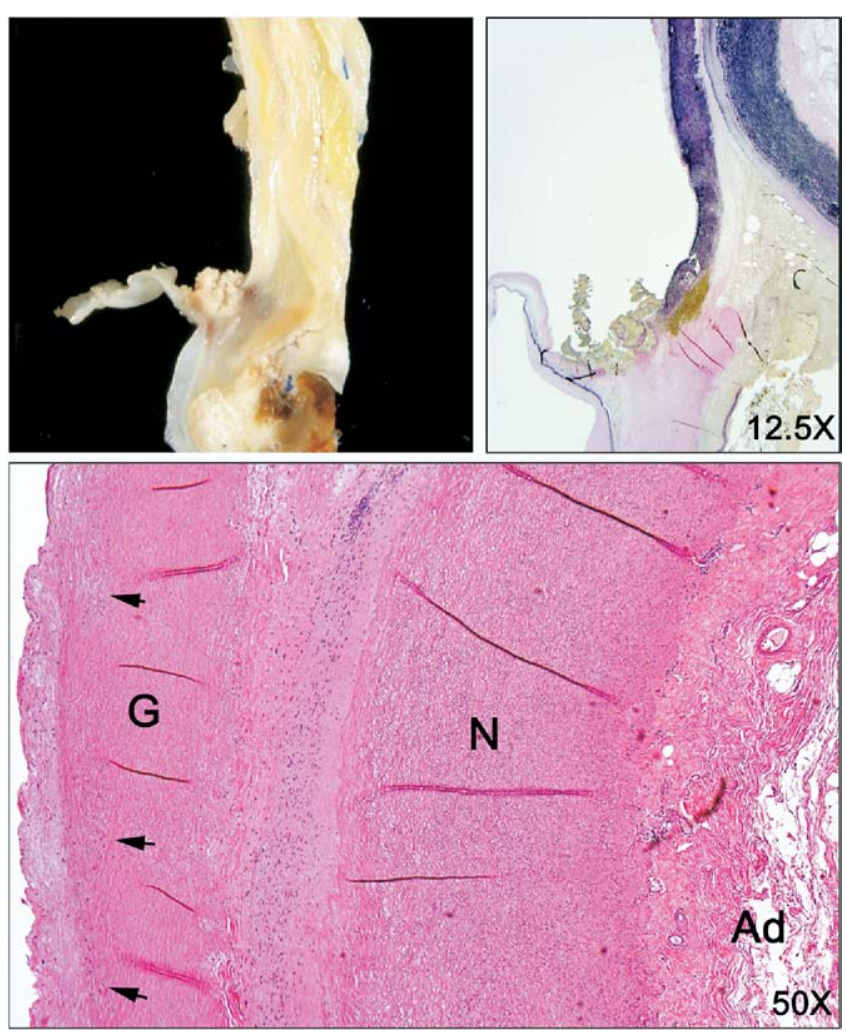

Figure 1. Gross and microscopic morphology of decellularized aortic homograft. Upper Left, Longitudinal section through homograft aortic root. The valve shows thin pliable cusps and focal calcification within valve pocket. Native aortic adventitia, periadventitial fat, and single blue suture are subjacent to graft (hematoxylin-eosin stain). Upper Right, Elastic media of both graft and native aorta. (Verhoeff-van Gieson stain.) Bottom, Cellularity of graft tissue. Absence of nuclei throughout decellularized graft tissue (G), except for neointima (far left) and superficial cell clusters within graft media (arrows). Cellularity of native aortic media ( $N$ ) and adventitia (Ad) is shown for comparison. (Hematoxylin-eosin stain.)

muscle differentiation in a subset of cells. While recellularization did not involve the full thickness of the aortic homograft wall in this study, there appeared to be a centrifugal propagation of cells, extending from the lumen outward, congruent with theories on circulating progenitor cells. ${ }^{4}$ Also salient was the virtual absence of calcification and inflammation. Calcification is common, even after 2 years, in conventional cryopreserved homografts. Although the relationship between graft allogenicity and in-vivo durability is controversial, the absence of an apparent active cellular immune
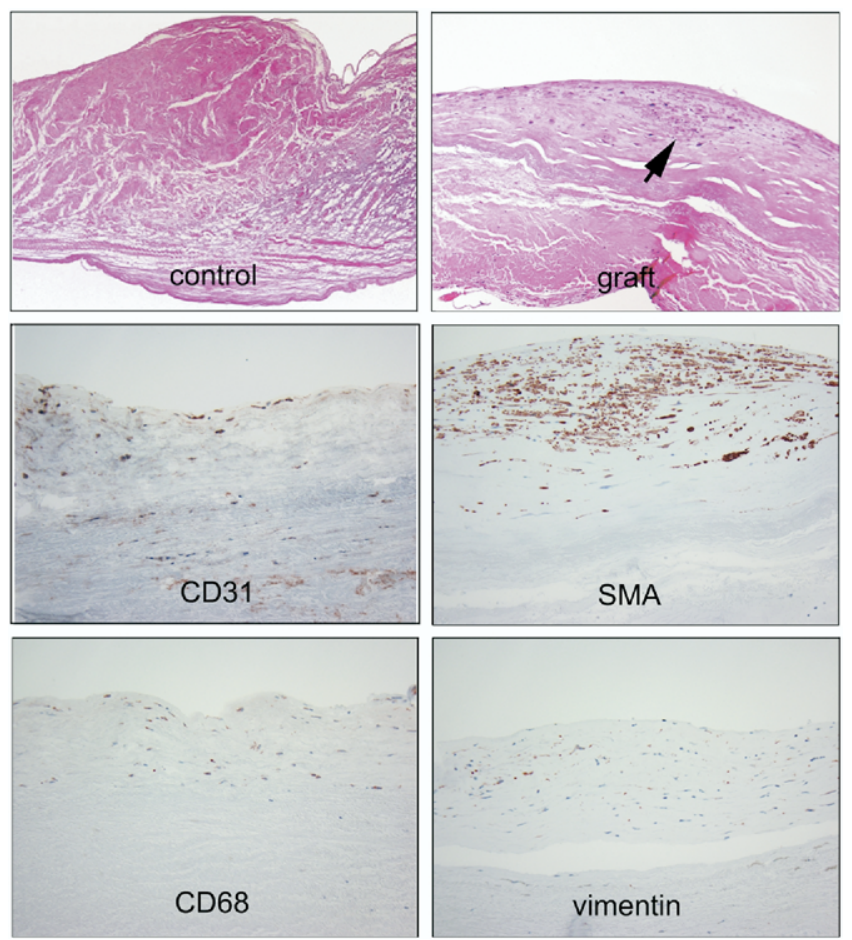

Figure 2. Histomorphology and immunohistochemical phenotype of the decellularized aortic homograft. Upper Left, Control sample of valve cusp from non-implanted SynerGraft. Upper Right, Cusp tissue from explanted SynerGraft. Patient's valve shows formation of cellular layer with infiltration of cells into body of valve cusp (arrow). Middle and Bottom, Expression of selected endothelial (CD31), smooth muscle (SM actin), macrophage (CD68), and fibroblastic (vimentin) antigens, as labeled.

response in this case is of interest in light of the minimal calcification and mild fibrosis.

\section{References}

1. Bechtel JF, Bartels C, Schmidtke C, Skibba W, Muller-Steinhardt M, Kluter H, et al. Does histocompatibility affect homograft valve function after the Ross procedure? Circulation, 2001;104(12 Suppl 1): I25-8.

2. Sayk F, Bos I, Schubert U, Wedel T and Sievers HH. Histopathologic findings in a novel decellularized pulmonary homograft: an autopsy study. Ann Thorac Surg, 2005;79(5):1755-8.

3. Elkins RC, Goldstein S, Hewitt CW, Walsh SP, Dawson PE, Ollerenshaw JD, et al. Recellularization of heart valve grafts by a process of adaptive remodeling. Semin Thorac Cardiovasc Surg, 2001;13(4 Suppl 1): 87-92.

4. Deb A., Wang SH, Skelding K, Miller D, Simper D and Caplice N. Bone marrow-derived myofibroblasts are present in adult human heart valves. J Heart Valve Dis, 2005;14(5):674-8. 
Table E1. Antibody clones and reaction conditions. [FOR ONLINE VIEWING ONLY]

\begin{tabular}{|c|c|c|c|c|}
\hline Antibody & Source* & Clone & Dilution & Antigen Retrieval \\
\hline CD3 & Cell Marque & Polyclonal & $1 / 200$ & Heat (EDTA) \\
\hline CD15 & Becton Dickinson & MMA & $1 / 10$ & Heat (Citrate) \\
\hline CD20 & Dako & L26 & $1 / 60$ & Heat (Citrate) \\
\hline CD31 & Dako & $\mathrm{JC} / 70 \mathrm{a}$ & $1 / 200$ & Heat (EDTA) \\
\hline CD34 & Becton Dickinson & My10 & $1 / 50$ & Heat (EDTA) \\
\hline CD68 & Dako & KP-1 & $1 / 200$ & Protease 2 \\
\hline Factor VIII & Dako & Polyclonal & $1 / 500$ & Protease 2 \\
\hline Smooth Muscle Actin & Dako & $1 \mathrm{~A} 4$ & $1 / 150$ & None \\
\hline Vimentin & Dako & 3B4 & $1 / 500$ & Protease 2 \\
\hline
\end{tabular}

*Sources - Cell Marque: Hot Springs, AR; Becton Dickinson: San Jose, CA; Dako: Carpinteria, CA. 